\title{
RESEARCH
}

\section{Low bone mineral density and fracture burden in postmenopausal women}

\author{
Ann Cranney MD MSc, Sophie A. Jamal MD PhD, James F. Tsang BSc, Robert G. Josse MB BS, \\ William D. Leslie MD MSc
}

\section{ABSTRACT}

Background: The study objectives were to determine fracture rates in relation to bone mineral density at various central skeletal sites, using the World Health Organization definition for osteoporosis (T-score $\mathbf{- 2 . 5}$ or less), and to contrast fracture patterns among women 50 to 64 years of age with those among women $\sigma_{5}$ years of age and older.

Methods: Historical cohort study with a mean observation period of 3.2 (standard deviation [SD] 1.5) years. The study group ( 16505 women 50 years of age or older) was drawn from the Manitoba Bone Density Program database, which includes all bone mineral density results for Manitoba. Baseline density measurements for the lumbar spine and hip were performed with dual-energy $x$-ray absorptiometry. Outcomes included the percentage of osteoporotic fractures and the rates of fracture and excess fracture (per 1000 person-years) among postmenopausal women with osteopenia and osteoporosis relative to those with normal bone mineral density (according to the classification of the World Health Organization).

Results: The mean age was $\sigma_{5}$ (SD 9) years, and the mean Tscores for all sites fell within the osteopenic category. There were $76_{5}$ incident fractures (fracture rate 14.5 [95\% confidence interval, $\mathrm{Cl}, 13 \cdot 5^{-15} .6$ [per 1000 person-years). Fracture rates were significantly higher among women $\sigma_{5}$ years of age or older than among women 50-64 years of age (21.6 [95\% Cl 19.723.4] v. 8.6 [95\% Cl 7.5-9.7] per 1000 person-years, $p<0.001$ ). Although fracture rates were significantly higher among women with osteoporotic T-scores, most fractures occurred in women with nonosteoporotic values (min-max: 59.7\%-67.8\%).

Interpretation: In this study, most of the postmenopausal women with osteoporotic fractures had nonosteoporotic bone mineral density values. This finding highlights the importance of considering key clinical risk factors that operate independently of bone mineral density (such as age) when assessing fracture risk.

Une version française de ce résumé est disponible à l'adresse www.cmaj.ca/cgi/content/full/177/6/575/DCI

CMAJ 2007;177(6):575-80

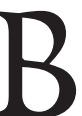

one mineral density is commonly used to diagnose osteoporosis and to predict individual fracture risk. ${ }^{1,2}$ The World Health Organization has proposed a diagnostic classification for bone mineral density based on the T- score (number of standard deviations above or below the mean for young adults), which recognizes 3 categories: normal (T-score -I or higher), osteopenia (T-score between -I and -2.5 ) and osteoporosis (T-score -2.5 or less). ${ }^{3}$ Although these definitions of osteoporosis and osteopenia were designed as diagnostic thresholds intended for populationbased analyses, many clinical guidelines have used them to define thresholds for treatment intervention for individual patients. ${ }^{4,5}$ Such recommendations may or may not be appropriate, depending on how fracture prevalence varies in relation to the thresholds of bone mineral density.

Population-based data on the percentage of fractures that occur in postmenopausal women with either normal bone mineral density or osteopenia are limited. Stone and colleagues, ${ }^{6}$ in a secondary data analysis of 9704 women over 65 years of age, reported that total hip bone mineral density was more strongly correlated with most fractures than were lumbar spine or peripheral bone mineral density measurements. Moreover, the percentage of fractures among women with osteoporosis (T-score $<-2.5$ ) was modest, ranging from less than $10 \%$ to $44 \% .{ }^{6}$ Siris and collaborators, ${ }^{7}$ in a cohort of I49 524 women over 50 years of age, used peripheral bone mineral density to determine the association between osteopenia and self-reported fractures. The prevalence of osteoporosis (T-score $-\mathbf{2 . 5}$ or less) was $6.4 \%$ among the women with fractures, and $\mathrm{I} 8 \%$ of all fractures occurred in these women.

In the current study, we determined fracture rates and the percentage of fractures among postmenopausal women in relation to bone mineral density at different central sites and in relation to the cut points defined by the World Health Organization; we also determined how fracture patterns differed between women $50-64$ years of age and those 65 years of age and older.

\section{Methods}

\section{Study design and patient population}

In this retrospective cohort study, we examined records for I6 505 women 50 years of age or older who underwent baseline bone mineral densitometry of the lumbar spine (first through fourth lumbar vertebrae) and the proximal femur (total hip, femoral neck and trochanter) between May 1998 and October

From the Ottawa Health Research Institute (Cranney), Ottawa, Ont.; the Department of Medicine, Division of Endocrinology and Metabolism (Jamal, Josse), St. Michael's Hospital, University of Toronto, Toronto, Ont.; and the Faculty of Medicine (Tsang, Leslie), University of Manitoba, Winnipeg, Man. 
2002. All of the women had medical coverage with Manitoba Health throughout the observation period, which ended Mar. 3I, 2004, and were included in the clinical database of the Manitoba Bone Density Program. ${ }^{8}$ The database includes all test results obtained by dual-energy x-ray absorptiometry since 1990 and is more than $99 \%$ complete and accurate, as judged by a chart audit. ${ }^{9}$ All clinical bone densitometry in the province of Manitoba, Canada, is performed within a single program structure that maintains uniform testing indications and reporting. The criteria for testing are consistent with published guidelines and highlight the importance of female sex, age 65 years or older, prior fragility fractures, prolonged corticosteroid use and other clinical risk factors in the decision of whether or not to test. ${ }^{4}$ Men were not included in the study group, because of small numbers and potential selection bias. The study was approved by the Research Ethics Board of the University of Manitoba and the Health Information Privacy Committee of Manitoba Health.

\section{Measurement of bone mineral density}

The lumbar spine $\mathrm{T}$-scores and $\mathrm{Z}$-scores (number of standard deviations above or below age-matched mean) used the US reference values for white women provided by the manufacturer of the absorptiometer. Hip T-scores and Z-scores were based on the revised reference data from the National Health and Nutrition Examination Survey (NHANES III) (calculated using the Prodigy version 8.8 densitometer, GE Lunar, Madison, Wis.). ${ }^{10}$ Bone densitometry was performed with I of the program's 2 primary instruments (DPX or Prodigy, GE Lunar). The instruments were cross-calibrated in vivo with 59 volunteers, and no clinically significant differences were identified (all T-score differences $<0.2$ ). Therefore, all analyses are based on the unadjusted numeric results generated by the instrument. For women with more than one densitometry record, the first measurement that included information for both spine and hip was used. Densitometers underwent daily assessment of stability with a spine phantom, and each demonstrated stable long-term performance (coefficient of variation [standard deviation $/$ mean] $<0.5 \%$ ).

\section{Ascertainment of incident fractures}

Physician claims processed by Manitoba Health and hospital databases record all health care utilization in the province. From these sources, we extracted information about patients' demographic characteristics, date and type of service provided, and diagnoses, coded according to the International Classification of Diseases, gth revision (Clinical Modification) (ICD-9$\mathrm{CM})$. Anonymous linkage of these databases to the bone mineral density database was accomplished by means of a unique scrambled health identification number and was successful in $99.4 \%$ of cases. ${ }^{9}$ Each subject's longitudinal health record was assessed from the date of bone density measurement to Mar. 3I, 2004, for the presence of the following ICD-9-CM fracture codes: hip (ICD-9-CM 820-82I), clinical spine (ICD-9-CM 805, defined below), forearm (ICD-9-CM 8I3) or proximal humerus (ICD-9-CM 8I2). We excluded traumatic fractures (ICD-9-CM E80o-E879 and E89o-E999). Nontraumatic fractures of the hip, clinical spine, forearm and proximal humerus were collectively designated as "osteoporotic fractures" and were included in our analysis. Clinical spine fracture refers to a fracture identified when a patient presents with back pain, and spinal radiography confirms fracture of the vertebral body. The accuracy of the data from Manitoba Health has previously been established for a number of clinical disorders, including osteoporotic fractures. ${ }^{11}$ Our use of administrative health data to define fractures in this way showed that the relation between bone mineral density and fractures in our clinical cohort was similar to that reported in a large meta-analysis. ${ }^{12}$

\section{Analysis}

Bone mineral density values were categorized as normal, osteopenic or osteoporotic according to the system of the World Health Organization; ${ }^{3} \mathrm{~T}$-scores were also grouped in increments of 0.5 across a wide range, from above 0 to -3.5 and below. The percentage of women with fractures and the fracture incidence rates per 1000 person-years (with 95\% confidence intervals [CIs]) were derived for the various T-score categories for each region of interest and for the minimum T-score (the lowest T-score of the 4 skeletal sites). The results were analyzed for the total sample and were then stratified into 2 age groups, 50-64 years and 65 years or older. Excess fracture risk was ex-

Table 1: Demographic characteristics of 16505 postmenopausal women in Manitoba who underwent bone mineral density testing between May 1998 and October 2002

\begin{tabular}{|c|c|c|c|}
\hline Characteristic & $\begin{array}{c}\text { Age } 50-64 \mathrm{yr} \\
n=8768\end{array}$ & $\begin{array}{c}\text { Age } \geq 65 \mathrm{yr} \\
n=7737\end{array}$ & $\begin{array}{c}\text { Overall } \\
n=16505\end{array}$ \\
\hline $\begin{array}{l}\text { No. of osteoporotic } \\
\text { fractures* }\end{array}$ & 245 & 520 & 765 \\
\hline Hip & 29 & 157 & 186 \\
\hline Spine & 63 & 145 & 208 \\
\hline Forearm & 66 & 123 & 189 \\
\hline Humerus & 92 & 136 & 228 \\
\hline Age, yr, mean (SD) & - & - & $65(9)$ \\
\hline$\%$ white & 97.7 & 98.8 & 98.2 \\
\hline $\begin{array}{l}\text { Height, cm, mean } \\
\text { (SD) }\end{array}$ & $161.6 \quad(6.4)$ & 159.0 & $160.4 \quad(6.7)$ \\
\hline $\begin{array}{l}\text { Weight, kg, mean } \\
\text { (SD) }\end{array}$ & $69.4(14.5)$ & $66.2(12.7)$ & $67.9(13.8)$ \\
\hline $\begin{array}{l}\text { Body mass index, } \\
\mathrm{kg} / \mathrm{m}^{2} \text {, mean }(\mathrm{SD})\end{array}$ & $26.6 \quad(5.4)$ & $26.2 \quad(4.8)$ & $26.4 \quad(5.1)$ \\
\hline $\begin{array}{l}\text { Follow-up, yr, } \\
\text { mean (SD) }\end{array}$ & $3.3 \quad(1.5)$ & $3.1 \quad(1.4)$ & $3.2 \quad(1.5)$ \\
\hline $\begin{array}{l}\text { Use of fan beam } \\
\text { scanner, } \%\end{array}$ & 70.9 & 75.7 & 73.2 \\
\hline \multicolumn{4}{|l|}{ T-score, mean (SD) } \\
\hline Lumbar spine & $-0.9(1.5)$ & $-1.6(1.6)$ & $-1.3(1.5)$ \\
\hline Femoral neck & $-1.2(0.9)$ & $-1.9(0.9)$ & $-1.5(1.0)$ \\
\hline Trochanter & $-1.0(1.1)$ & $-1.6(1.2)$ & $-1.3(1.2)$ \\
\hline Total hip & $-0.7(1.1)$ & $-1.5(1.1)$ & $-1.1(1.2)$ \\
\hline Minimum $†$ & $-1.6(1.0)$ & $-2.3(1.1)$ & $-1.9(1.1)$ \\
\hline
\end{tabular}

Note: $\mathrm{SD}=$ standard deviation.

*Some patients had more than 1 type of fracture.

†Minimum refers to the lowest T-score of the 4 skeletal sites. 
amined by site of bone mineral density testing and was defined as the fracture rate for those with reduced bone mineral density (osteopenic or osteoporotic T-score) minus the fracture rate for those with normal bone mineral density. ${ }^{13}$ Similarly, odds ratios (OR) for fracture were derived for those with reduced bone mineral density (osteopenic or osteoporotic T-score) relative to those with normal values. Continuous data are expressed as mean (and SD) unless otherwise stated. A $p$ value of less than 0.05 was used to determine statistical significance.

\section{Results}

\section{Population characteristics}

The mean age of the 16505 women in the cohort was 65 (SD 9) years (Table I). Forty-seven percent $(n=7737)$ of the women were 65 years of age or older. The majority of the women were white (98.2\%), with small percentages of other ethnic groups (I.3\% Asian and 0.3\% black). Mean weight was 67.9 (SD I3.8) $\mathrm{kg}$, and mean height was I6o.4 (SD 6.7) $\mathrm{cm}$. The mean Tscores for all measurement sites were within the osteopenic interval and were significantly lower among women 65 years of age or older than among women 50-64 years of age $(p<$ 0.001 ). Z-scores for all skeletal sites were close to zero (range -O.I to +o.I), which indicates that the average bone mineral density was close to the manufacturer's age-matched reference.

\section{Outcomes}

Over the mean follow-up period of 3.2 (SD I.5) years, a total of 765 (4.6\%) women experienced a fracture, which corresponds to an overall fracture rate of I4.5 (95\% CI I3.5-I5.5) per Iooo person-years. Of these 765 osteoporotic fractures, $520(68 \%)$ occurred in women 65 years of age or older. Although fracture rates in both age groups were highest among women with osteoporosis, most fractures occurred in women with normal bone mineral density or osteopenia. Figure I illustrates the continuous relation between higher fracture

\section{A. Lumbar spine}

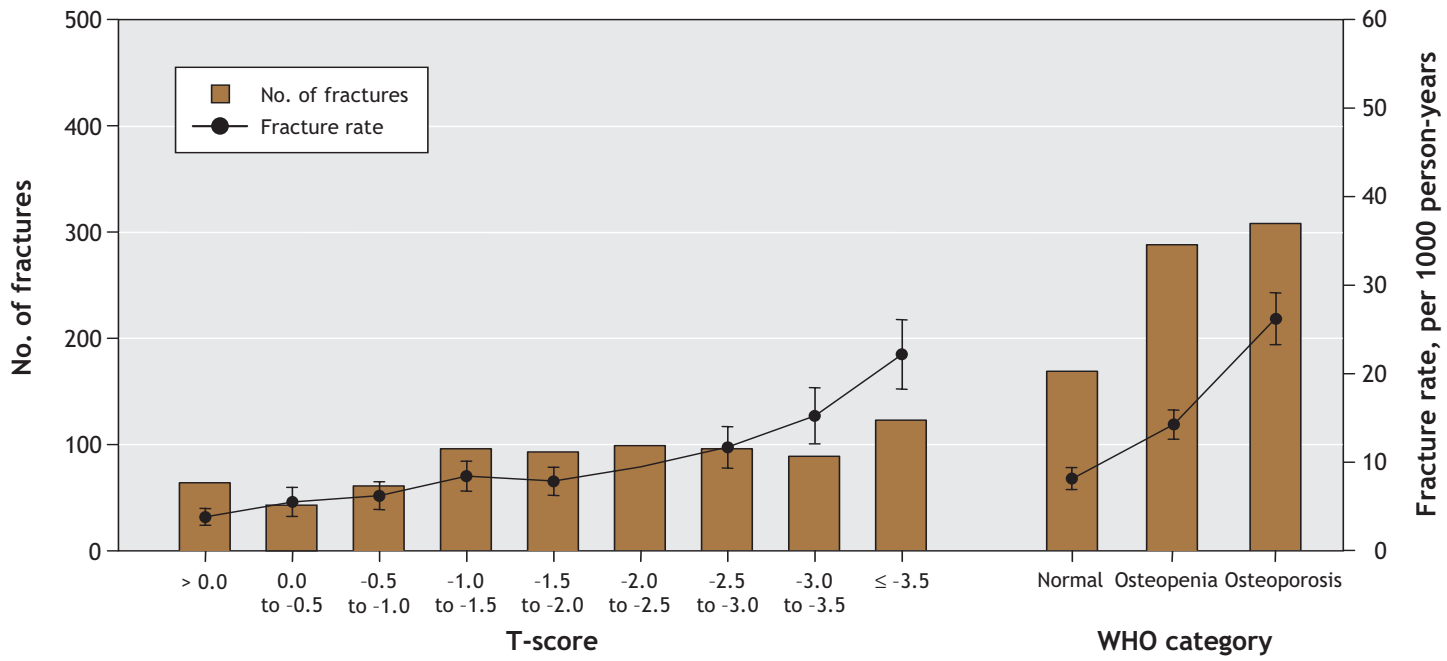

B. Total hip

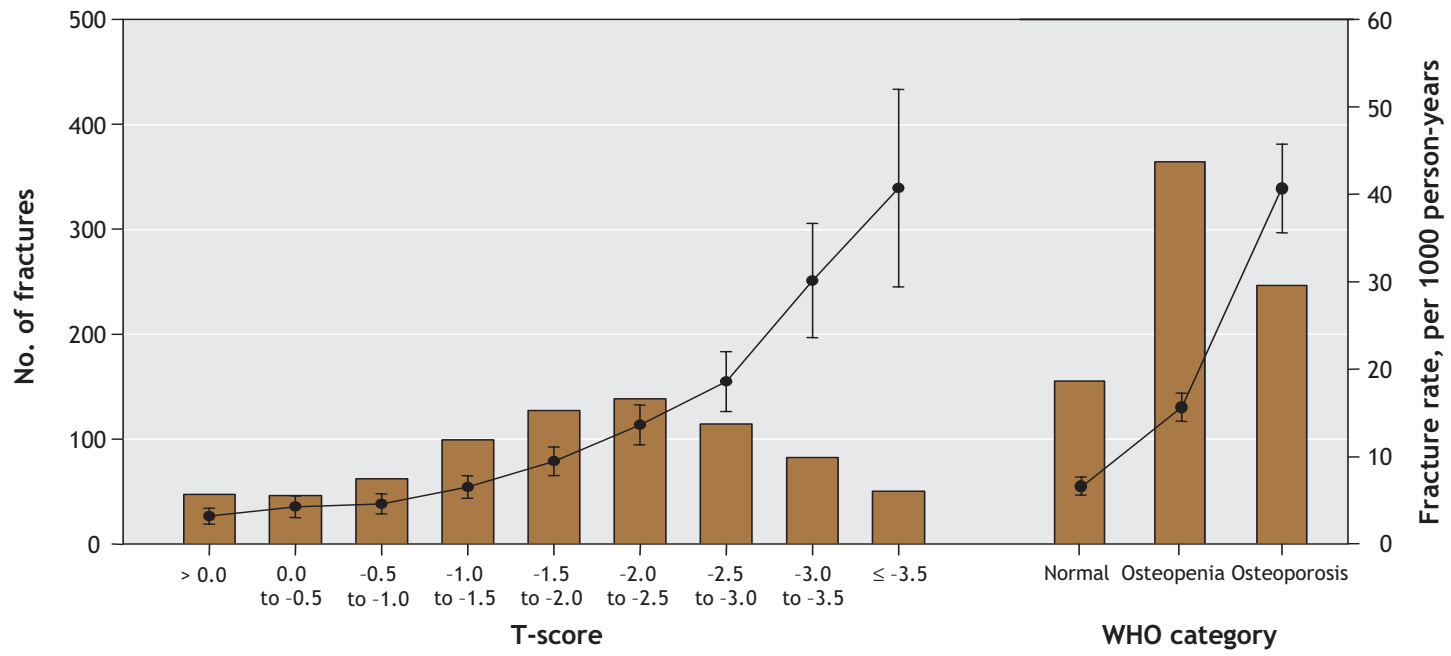

Figure 1: Number of fractures and fracture rate (per 1000 person-years, with $95 \%$ confidence intervals) by lumbar spine (A) and total hip (B) bone mineral density T-score and World Health Organization category. 
rates and lower bone mineral density, the highest fracture rates being associated with the lowest T-scores. Depending on the measurement site used, $59.7 \%$ to $67.8 \%$ of fractures that occurred after assessment of bone mineral density involved women who had nonosteoporotic values. The percentage of fractures that occurred in association with nonosteoporotic T-scores was greater among women 50-64 years of age $(75.5 \%-86.5 \%)$ than among women over 65 years of age $(50.6 \%-59.0 \%)$. When we used the threshold T-score for intervention of the National Osteoporosis Foundation $(-2.0)$, the percentage of osteoporotic fractures occurring among those with T-scores above the threshold was $40 \%$ to $50 \% .^{5}$

We used the lumbar spine results to define World Health Organization categories for the overall sample and found that $22 \%$ of the fractures (8.2 per Iooo person-years) occurred in women with normal bone mineral density, 38\% (I4.3 per 1000 personyears) in women with osteopenia and 40\% (26.2 per 1000 person-years) in women with osteoporosis. Fracture incidence rates in women with osteoporotic bone mineral density at different hip sites ranged from 33.4 (95\% CI 29.6-37.2) to 40.6 (95\% CI 35.6-45.7) per rooo person-years (Figure I, Table 2), compared with 26.2 (95\% CI 23.2-29.I) per Iooo person-years for those with osteoporotic values for the lumbar spine. Excess fracture rates for osteoporotic or osteopenic bone mineral density values relative to normal values were much higher at the total hip than at the lumbar spine (34.0 [95\% CI 28.8-39.2] v. I8.0 [95\% CI I4.9-2I.2) per Iooo person-years) (Table 3).

Overall fracture rates were significantly higher among

\begin{tabular}{|c|c|c|c|}
\hline Site* & Age $50-64 \mathrm{yr}$ & Age $\geq 65 \mathrm{yr}$ & Overall \\
\hline \multicolumn{4}{|l|}{ Normal } \\
\hline Lumbar spine & $5.6 \quad(5.4-6.9)$ & $12.9(10.3-15.5)$ & $8.2 \quad(6.9-9.4)$ \\
\hline Total hip & $5.3 \quad(4.2-6.5)$ & $9.4 \quad(7.2-11.6)$ & $6.6 \quad(5.6-7.7)$ \\
\hline Femoral neck & $4.0 \quad(2.8-5.3)$ & $9.2 \quad(6.0-12.3)$ & $5.4 \quad(4.1-6.6)$ \\
\hline Trochanter & $5.2(4.0-6.4)$ & $10.4 \quad(8.0-12.8)$ & $7.0 \quad(5.9-8.2)$ \\
\hline Minimum & $4.2 \quad(2.7-5.7)$ & $9.3 \quad(5.4-13.2)$ & $5.4 \quad(4.0-6.9)$ \\
\hline \multicolumn{4}{|l|}{ Osteopenic } \\
\hline Lumbar spine & $9.9 \quad(8.0-11.8)$ & $19.4(16.6-22.3)$ & $14.3(12.6-15.9)$ \\
\hline Total hip & $11.4 \quad(9.4-13.4)$ & $19.6(17.1-22.1)$ & $15.7(14.1-17.3)$ \\
\hline Femoral neck & $10.4 \quad(8.8-12.0)$ & $16.3(14.2-18.4)$ & $13.2(11.9-14.5)$ \\
\hline Trochanter & $9.8 \quad(8.0-11.5)$ & 18.0 & $13.7(12.2-15.1)$ \\
\hline Minimum & $8.2 \quad(6.8-9.6)$ & $13.2(11.0-15.3)$ & $10.3 \quad(9.0-11.5)$ \\
\hline \multicolumn{4}{|l|}{ Osteoporotic } \\
\hline Lumbar spine & 14.7 (11.0-18.5) & $32.3(28.3-36.3)$ & $26.2(23.2-29.1)$ \\
\hline Total hip & $22.4(14.7-30.0)$ & $46.6(40.3-52.8)$ & $40.6(35.6-45.7)$ \\
\hline Femoral neck & 15.7 (10.7-20.8) & $39.8(34.9-44.7)$ & $33.4(29.6-37.2)$ \\
\hline Trochanter & $19.9(14.5-25.4)$ & $43.1(37.6-48.6)$ & $35.8(31.7-39.9)$ \\
\hline Minimum & $15.0(11.9-18.2)$ & $32.8(29.3-36.2)$ & $26.6(24.1-29.0)$ \\
\hline Overall & $8.6 \quad(7.5-9.7)$ & $21.6(19.7-23.4)$ & $14.5(13.5-15.6)$ \\
\hline
\end{tabular}

*Sites categorized by bone mineral density, as defined by the World Health Organization: ${ }^{3}$ normal $=\mathrm{T}$-score -1 or above, osteopenia $=\mathrm{T}$-score between -1 and -2.5 , osteoporosis $=\mathrm{T}$-score -2.5 or less.

Table 3: Excess fracture rate per 1000 person-years (95\% confidence interval) among women with osteopenic and osteoporotic bone mineral density relative to fracture rate among women with normal bone mineral density at the particular site, by age group

\begin{tabular}{|c|c|c|c|c|c|c|}
\hline \multirow[b]{2}{*}{ Site } & \multicolumn{2}{|c|}{ Age $50-64 \mathrm{yr}$} & \multicolumn{2}{|c|}{ Age $\geq 65 \mathrm{yr}$} & \multicolumn{2}{|c|}{ Overall } \\
\hline & Osteopenic & Osteoporotic & Osteopenic & Osteoporotic & Osteopenic & Osteoporotic \\
\hline Femoral neck & $6.3(4.3-8.3)$ & $11.7(6.5-16.9)$ & $7.2(3.3-10.9)$ & $30.6(24.8-36.5)$ & $7.8(6.0-9.6)$ & $28.0(24.0-32.0)$ \\
\hline Trochanter & $4.5(2.4-6.7)$ & $14.7(9.1-20.4)$ & $7.6(4.2-11.0)$ & $32.7(26.7-38.6)$ & $6.6(4.8-8.5)$ & $28.8(24.5-33.0)$ \\
\hline
\end{tabular}


women at least 65 years of age than among younger women (21.6 [95\% CI 19.7-23.4 v. 8.6 [95\% CI 7.5-9.7] per 1000 person-years) (Table 2). Even within each World Health Organization category, older women had significantly greater fracture rates (Table 2). Excess fracture rates among those with osteoporotic values (relative to those with normal values) were higher for women over 65 years of age (min-max: $19.4-37.1$ per 1000) than for those 50-64 years of age (min-max: 9.I-I7.0 per Iooo person-years) (Table 3). Overall odds ratios for fracture among women with osteoporotic values (relative to those with normal values) were significantly greater ( 3.52 to 6.85 per 1000 person-years) than those for women with osteopenic values (I.83 to 2.59 per Iooo person-years).

\section{Interpretation}

Our findings confirm that although there is a strong relation between low bone mineral density and increased fracture risk, with higher fracture rates observed among women with osteoporosis (as defined on the basis of bone mineral density), fractures occurred more commonly in women with normal or osteopenic values, since more women fall into these categories. Suprisingly, although we found that, among those with osteoporotic T-scores, fracture rates were higher among women at least 65 years of age than among those 50-64 years of age, over $60 \%$ of fractures occurred in younger women with T-scores greater than $\mathbf{- 2 . 5}$. We also found that excess fracture rates by T-score category were highest when using the total hip bone data, which suggests that T-scores for this site might afford greater stratification of fracture risk than the lumbar spine $\mathrm{T}$-score or the minimum $\mathrm{T}$-score. This finding differs from what is currently recommended in the Canadian reporting guidelines for bone mineral density. ${ }^{14}$

Our findings are consistent with those of other authors, who have reported that the majority of fractures occur in postmenopausal women with T-scores above $-2 \cdot 5 \cdot \cdot^{6,7,15}$ Compared with these other studies, the strengths of our study include use of multiple central sites for dual x-ray absorptiometry and confirmation of fractures by radiography. ${ }^{7}$

Our study had a number of limitations. The study group was selected on the basis of physician referral for bone mineral densitometry and was not a random sample of the general population in Manitoba. However, our use of a regionally based clinical cohort reflects the population in which such testing is typically used in clinical practice. Ascertainment of fractures from administrative databases has limitations, particularly the potential misclassification of traumatic and nontraumatic fractures and the underreporting of minor fractures. Many vertebral fractures go undiagnosed, since more than $65 \%$ of spine fractures do not cause obvious symptoms. ${ }^{16}$ Underrepresentation of vertebral fractures as a percentage of all fractures could partly explain why the total hip T-score captured a higher percentage of osteoporotic fractures than did the lumbar spine T-score.

This study highlights the fact that most fractures occur in women with normal or osteopenic bone mineral density. If treatment decisions are based on bone mineral density values alone, many of these women would not receive treatment. ${ }^{4,5}$ This is concerning, because a history of fracture indicates an increase in risk of future fractures (by I.5 to 2.0 times), regardless of bone density. ${ }^{17}$ As such, treatment decisions should be based not only on the T-score but also on overall fracture risk.

Until recently, clinical guidelines have made little distinction between osteoporosis as defined by the T-score and fracture risk. As a result, older patients with fragility fractures who did not have osteoporosis, as defined by the World Health Organization criteria, may not have received treatment. ${ }^{18}$ Our study supports the concept that bone mineral density captures only one aspect of fracture risk, namely the quantity of bone, and that other factors that may influence bone strength or the risk of falls are also contributors to fracture risk. For example, prospective studies have consistently demonstrated that clinical risk factors such as age, prior fracture, a family history of osteoporosis and corticosteroid use contribute to fracture risk, independent of bone density as determined by absorptiometry. ${ }^{10-21}$ The assessment of a patient's fracture risk could be enhanced by considering the clinical risks, especially for people who are at moderate risk on the basis of bone mineral density alone..$^{22-24}$

Our findings suggest that osteoporosis treatment guidelines should be modified to allow for targeted case-finding, whereby a combination of clinical risk factors (e.g., prior fracture and age) and bone mineral density could be used to derive an individual's Io-year probability of fracture and hence the overall risk of fracture..$^{17,25}$ Clinicians could then use the absolute fracture risk to guide treatment decisions, in a manner similar to the way in which clinical risk factors are combined with laboratory data to stratify risk and guide therapy in cardiovascular disease.

The World Health Organization is currently developing algorithms that will incorporate clinical risk factors into the calculation of Io-year fracture risk. The Scientific Advisory Board of Osteoporosis Canada and the Canadian Association of Radiologists both recommend that bone mineral density results be reported in the context of clinical risk factors, such as age, sex, prior fracture history and steroid use, which can then be used to generate a Io-year prediction of fracture risk..$^{14}$ This approach will increase our ability to accurately identify men and women at high risk for fracture and to appropriately guide treatment decisions.

This article has been peer reviewed.

Competing interests: None declared for Sophie Jamal and James Tsang Anne Cranney has received speaker fees from Merck Frosst Canada, SanofiAventis, P\&G Pharmaceuticals Canada and Eli Lilly Canada. Robert Josse has received speaker fees from or has been a member of advisory boards for $P \& G$ Pharmaceuticals Canada, Sanofi-Aventis, Novartis, Servier, Eli Lilly Canada and Merck Frosst Canada. William Leslie has received speaker fees and unrestricted educational and research grants from Sanofi-Aventis, P\&G Pharmaceuticals Canada and Merck Frosst Canada.

Contributors: All of the authors were involved in the conception of the study, provided input on the interpretation of the data, contributed to the writing and revising of the manuscript and approved the version to be published.

Acknowledgements: We are indebted to Manitoba Health for providing the data used in this study, Charles Burchill for assistance with data extraction, and Drs. Patricia Caetano and Lisa Lix for advice about the analysis. The results and conclusions are those of the authors, and no official endorsement by Manitoba Health is intended or should be inferred. This article has been reviewed and approved by the members of the Manitoba Bone Density Program Committee.

The study was funded in part by an unrestricted educational grant from the CHAR/GE (Canadian Heads of Radiology/General Electric) Healthcare Development Awards Programme. Drs. Cranney and Jamal have Investigator awards from the Canadian Institutes of Health Research. 


\section{REFERENCES}

I. Marshall D, Johnell O, Wedel H. Meta-analysis of how well measures of bone min eral density predict occurrence of osteoporotic fractures. BMJ I996;312:1254-9.

2. Cummings SR, Black DM, Nevitt MC, et al. Bone density at various sites for prediction of hip fractures. The Study of Osteoporotic Fractures Research Group. Lancet I993;34I:72-5.

3. Assessment of fracture risk and its application to screening for postmenopausal osteoporosis. Report of a WHO Study Group. World Health Organ Tech Rep Ser I994;843:I-I29.

4. Brown JP, Josse RG. 2002 clinical practice guidelines for the diagnosis and management of osteoporosis in Canada. CMAJ 2002;167(Suppl):SI-34

5. National Osteoporosis Foundation. Physician's guide to prevention and treatment of osteoporosis. Washington: The Foundation; 2003

6. Stone KL, Seeley DG, Lui LY, et al. BMD at multiple sites and risk of fracture of multiple types: long-term results from the Study of Osteoporotic Fractures. J Bone Miner Res 2003;18:1947-54.

7. Siris ES, Chen YT, Abbott TA, et al. Bone mineral density thresholds for pharmacological intervention to prevent fractures. Arch Intern Med 2004;164:II08-12.

8. Leslie WD, Metge C. Establishing a regional bone density program: lessons from the Manitoba experience. JClin Densitom 2003;6:275-82.

9. Leslie WD, Caetano PA, Macwilliam LR, et al. Construction and validation of a population-based bone densitometry database. J Clin Densitom 2005;8:25-30.

o. Binkley N, Kiebzak GM, Lewiecki EM, et al. Recalculation of the NHANES database SD improves T-score agreement and reduces osteoporosis prevalence. J Bone Miner Res 2005;20:195-20I.

II. Roos LL, Walld RK, Romano PS, et al. Short-term mortality after repair of hip fracture. Do Manitoba elderly do worse? Med Care 1996;34:310-26.

I2. Leslie WD, Tsang JF, Caetano PA, et al. Effectiveness of bone density measurement for predicting osteoporotic fractures in clinical practice. J Clin Endocrinol Metab 2007;92:77-8I.

13. Siris ES, Brenneman SK, Barrett-Connor E, et al. The effect of age and bone mineral density on the absolute, excess, and relative risk of fracture in postmenopausa women aged 50-99: results from the National Osteoporosis Risk Assessment (NORA). Osteoporos Int 2006;17:565-74

I4. Siminoski K, Leslie WD, Frame H, et al. Recommendations for bone mineral density reporting in Canada. Can Assoc Radiol J 2005;56:178-88.

15. Schuit SC, van der Klift M, Weel AE, et al. Fracture incidence and association with bone mineral density in elderly men and women: the Rotterdam Study. Bone 2004; 34:195-202

I6. Lentle BC, Brown JP, Khan A, et al. Recognizing and reporting vertebral fractures: reducing the risk of future osteoporotic fractures. Can Assoc Radiol J 2007;58:27-36.

I7. Kanis JA, Borgstrom F, De Laet C, et al. Assessment of fracture risk. Osteoporos Int 2005; $16: 58 \mathrm{I}-9$

I8. Miller PD. Guidelines for the diagnosis of osteoporosis: T-scores versus fractures. Rev Endocr Metab Disord 2006;7:75-89.

I9. Kanis JA, Johansson $\mathrm{H}$, Oden A, et al. A family history of fracture and fracture risk: a meta-analysis. Bone 2004;35:1029-37.

20. Kanis JA, Johnell O, De Laet C, et al. A meta-analysis of previous fracture and subsequent fracture risk. Bone 2004;35:375-82.

2I. Kanis JA, Johansson $\mathrm{H}$, Oden A, et al. A meta-analysis of prior corticosteroid use and fracture risk. J Bone Miner Res 2004;19:893-9.

22. Sornay-Rendu E, Munoz F, Garnero P, et al. Identification of osteopenic women at high risk of fracture: the OFELY study. J Bone Miner Res 2005;20:18I3-9.

23. Miller PD, Barlas S, Brenneman SK, et al. An approach to identifying osteopenic women at increased short-term risk of fracture. Arch Intern Med 2004;I64:III3-20.

24. De Laet $\mathrm{C}$, Oden A, Johansson $\mathrm{H}$, et al. The impact of the use of multiple risk indicators for fracture on case-finding strategies: a mathematical approach. Osteoporos Int 2005; 6 :313-8.

25. Black DM, Steinbuch M, Palermo L, et al. An assessment tool for predicting fracture risk in postmenopausal women. Osteoporos Int 200I;12:519-28.

Correspondence to: Dr. Ann Cranney, Clinical Epidemiology

Program, Ottawa Health Research Institute, Rm. ASB I-oog,

I053 Carling Ave., Ottawa ON KIY 4E9; ancranney@ohri.ca

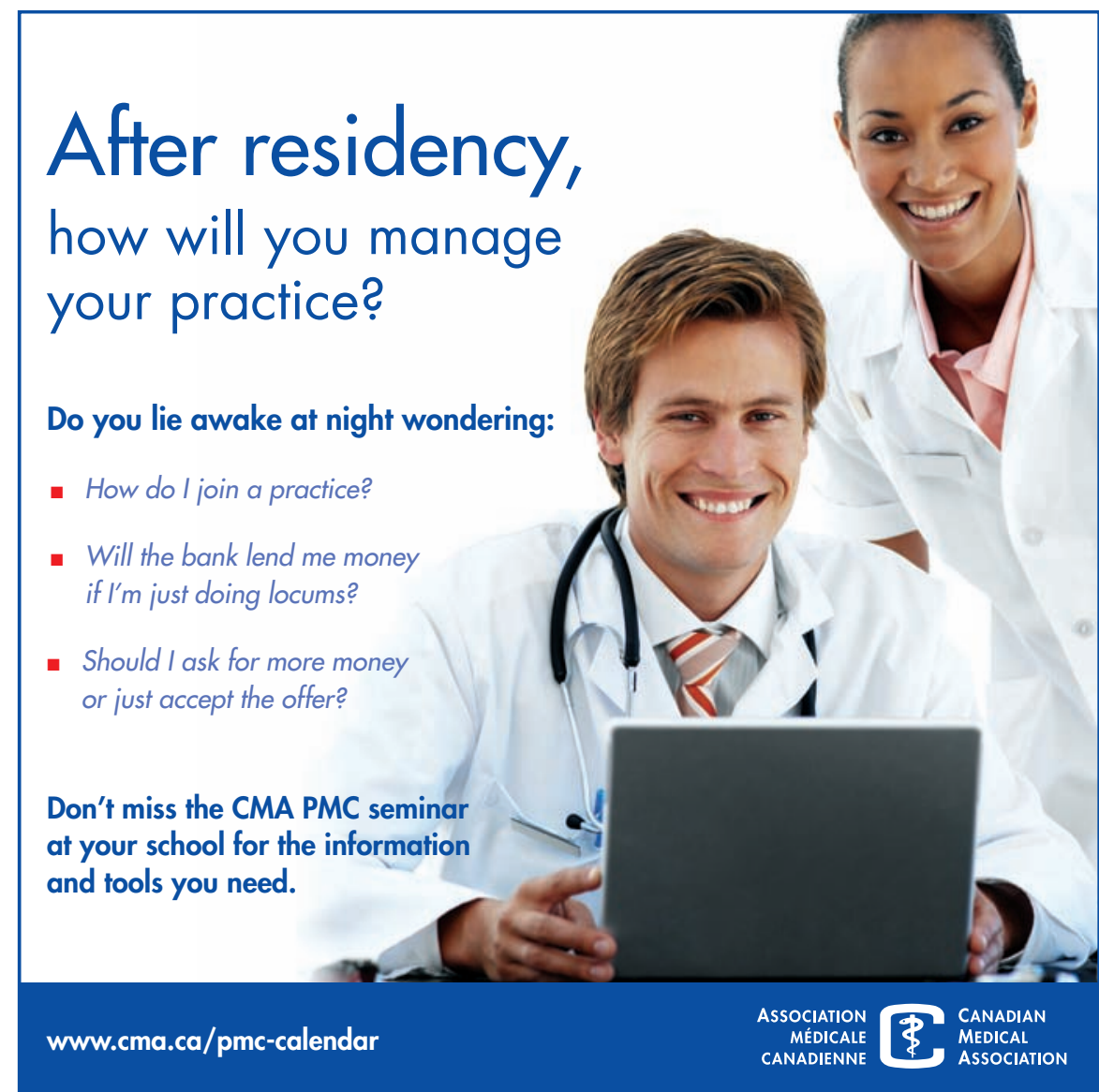

